www.jmscr.igmpublication.org

Impact Factor (SJIF): 6.379

Index Copernicus Value: 71.58

ISSN (e)-2347-176x ISSN (p) 2455-0450

crossref DOI: _https://dx.doi.org/10.18535/jmscr/v6i3.211

Journal Of Medical Science And Clinical Research

IGM Publication

An Official Publication of IGM Publication

\title{
A comparative evaluation of three different methods used to achieve local anaesthesia for fiberoptic guided intubation under sedation
}

\author{
Authors \\ Naresh Kumar Sharma ${ }^{1}$, Kiwi Mantan ${ }^{2}$, Sangeeta Sethia ${ }^{3}$, Sadhana Jain ${ }^{4}$, \\ Vishal Devra ${ }^{5}$ \\ ${ }^{1}$ Resident, ${ }^{2}$ Assistant Professor, ${ }^{3}$ Medical Officer, ${ }^{4}$ Senior Professor, ${ }^{5}$ Assistant Professor \\ Department of Anaesthesia, Sardar Patel Medical College \& AGH, Bikaner, Rajasthan \\ Corresponding Author \\ Naresh Kumar Sharma \\ Resident, Department of Anaesthesia, Sardar Patel Medical College \& AGH, Bikaner, Rajasthan \\ Email: nareshkumar160289@gmail.com
}

\begin{abstract}
Background and Aim: Fiberoptic intubation is the gold standard technique for airway management in patients with difficult standard direct laryngoscopy, performed either awake or under sedation. The aim of sedation is to facilitate patient comfort and satisfaction, and to alleviate patient anxiety. Aim of this prospective randomized comparative study was to compare three different methods of topical anaesthesia under sedation, namely transcricoid injection, spray as you go, nebulisation of lignocaine with respect to intubation grading scale, severity scale, intubation time and complications in patients undergoing intubation.

Methodology: Ninety ASA grade 1 or 2 patients of either sex aged 20-50 yrs scheduled for elective surgery were equally divided into three groups $(n=30)$, received $0.1 \%$ xylometazoline in both nostrils then $10 \%$ lignocaine by spraying the nares and posterior pharyngeal wall. Thereafter patients received $4 \mathrm{ml}$ of $4 \%$ lignocaine either by trancscricoid injection in group A, or via spray as you go method in group B, or via nebulization 15 min prior to procedure in group $C$. Intubation time, intubation grading scale, grading of overall intubating condition, cough counts, stridor, extra local anaesthetic requirement and were recorded. Patients were asked to score the procedure using severity score. Patients were monitored continuously for vital parameters blood pressure, SpO2, ECG, pulse rate.

Results: Group A patients showed better severity scale $(p<0.01)$, shorter intubation time, lower incidence of coughing and stridor, didnot require extra dose of local anaesthetic and were maintained PR, BP, SpO2. The endoscopist intubation grading scale and grading of overall intubating conditions were better in Group $A(p<0.01)$ than Group B\&C.

Conclusion: In conclusion transcricoid injection of local anaesthetic was safe, providing effective local anaesthesia and was preferred by both patient and endoscopist.

Keywords: Fiberoptic intubation, lignocaine.

Introduction for whom standard direct laryngoscopy is difficult

Fiberoptic intubation of trachea is an established or unsafe ${ }^{1}$. The principal patient's complains in technique for obtaining a secure airway in patients fiberoptic intubation include sensation of
\end{abstract}


instrumentation through nose and larynx, pain and coughing while endoscopist ascribe difficulty in laryngeal visualization to secretion and inadequate local anaesthesia. The technical success of fiberoptic intubation and patient's tolerance depends on both operator experience as well as effectiveness of topical anaesthesia and obtundation of pharyngeal, laryngeal and tracheobronchial reflexes ${ }^{2,3}$.

Complete airway anaesthesia increases patient comfort and probability of success, decreases the response to intubation. Prior to intubation, while the upper airway is commonly anaesthetized by local lignocaine spray or gel, the modalities to anaesthetize larynx and lower respiratory tract include injection via fiberoptic bronchoscope, transcricoid injection and delivery via a nebulizer $^{4-6}$.

Fiberoptic intubation can be performed either awake or under sedation. The aim of sedation is to facilitate patient comfort and satisfaction, and to alleviate patient anxiety, cough and to reduce complication $^{7,8}$. Combined opiates and benzodiazepines or propofol are frequently used to achieve sedation during fiberoptic intubation. Due to rapid onset and amnestic properties propofol is an appealing agent for procedural sedation $^{9,10}$.

Aim of our prospective randomized comparative study was to compare three different methods of topical anaesthesia under sedation, namely transcricoid injection, spray as you go, nebulization of lignocaine. The primary objective was to compare the intubation time of the techniques, complications and the secondary objectives were to assess the quality of airway anesthesia, patient comfort.

\section{Material \& Methods}

After approval from ethical committee 90 adult patients of both sexes aged 20-60 years with ASA status I-II undergoing surgery under general anesthesia, were randomly selected. Patients who did not provide consent, had an allergy to any study drug, pregnant, asthmatic, epileptic, hemodynamically unstable or deranged coagulation profile were excluded from the study. After preanaesthesia checkup and a written informed consent, all patients were kept nil by mouth on the night before surgery. Routine investigations like hemogram, blood sugar, blood urea, serum creatinine, bleeding time, clotting time, chest x-ray, ECG were done.

In theatre all patients received injection glycopyrrolate $5 \mathrm{ug} / \mathrm{kg}$ IV. $0.1 \%$ xylometazoline 2 drops were instilled in both nostrils. After checking patencies both nasal passages were lubricated with $2 \mathrm{ml}$ of $2 \%$ lignocaine jelly. Posterior pharynx was anaesthetized with 4 sprays of $10 \%$ lignocaine and the patients were asked to gargle with the excess solution trickling down the throat. An intravenous access was established and monitoring instituted with pulse oximetry, ECG, $\mathrm{SpO}_{2}$, and noninvasive blood pressure.

The next step was aimed at achieving laryngotracheal anaesthesia prior to intubation. Group A $(\mathrm{n}=30)$ patients had $4 \mathrm{ml}$ of $4 \%$ lignocaine injected through the cricothyroid membrane. Group B $(n=30)$ patients had the intubating fiberscope inserted transnasally until just above the cords and $4 \mathrm{ml}$ of $4 \%$ lignocaine was administered through suction channel. This was done in two steps: the first onto the vocal cords and the second into the trachea during inspiration. Group C $(\mathrm{n}=30)$ patients had $4 \mathrm{ml}$ of $4 \%$ lignocaine delivered by nebulizer started 20 minutes before the procedure and took 10 minutes to complete. In each group additional 1-2 ml aliquots of $4 \%$ lignocaine was administered if required. After passing through the vocal cords the fibroscope was advanced until tracheal rings were in view, injection propofol $1 \mathrm{mg} / \mathrm{kg}$ IV was given to all patients and endotracheal tube was advanced.

Vital parameters were observed at 1,3,5,10 min interval. Intubation time was defined as the time from passing the flexible fiberoptic bronchoscope tip through the nostril to the first reading obtained by the capnograph after endotracheal intubation. Intubation grading scale by observer incidence of 
cough, stridor, extra lignocaine dose were noted. Severity scale by patients recorded after procedure.

Intubation grading scale (observer)

$0=$ No coughing/gagging in response to intubation

$1=$ Mild coughing/gagging that did not hinder intubation

$2=$ Moderate coughing/gagging that interfered minimally with intubation

$3=$ Severe coughing/gagging that made intubation difficult

4 = Severe coughing/gagging, required additional local anaesthesia and/or other change in technique.

Severity scale (reported by patient)

Not unpleasant 1

Uncomfortable 2

Unpleasant 3

Most unpleasant 4

Intolerable 5

General anesthesia was achieved with propofol (2 $\mathrm{mg} / \mathrm{kg} \mathrm{IV})$ and vecuronium bromide $(0.1 \mathrm{mg} / \mathrm{kg}$ IV).

\section{Results}

Results were expressed as mean \pm standard deviation. ANOVA test for demographic data, and hemodynamic parameters and Chi square test was applied for nonparametric data like intubation grading scale, severity scale, grading of overall intubating condition. Sample size was calculated to be 30 patients in each group to demonstrate a $40 \%$ difference in intubation time with a power of 0.8 and type 1 error of 0.05 . To allow for study error and attrition, a total of 90 patients were included in this study.

All patients were demographically similar. Base line pulse was $78.40 \pm 4.61 \mathrm{bpm}$ in Group A, $80.73 \pm 6.00 \mathrm{bpm}$ in Group B and $78.53 \pm 6.00$ $\mathrm{bpm}$ in Group C. The maximum rise in pulse rate in Group A was 89.36 6.24 bpm, in Group B was $101.10 \pm 12.09 \mathrm{bpm}$ and in Group C was 97.40 $12.23 \mathrm{bpm}$.
Base line MAP was 92.73. \pm 5.64 mmHg in Group A, 94.46 $\pm 5.82 \mathrm{mmHg}$ in Group B and 92.33 \pm $7.32 \mathrm{mmHg}$ in Group C. In Group A the MAP increased up to $99.33 \pm 6.33 \mathrm{mmHg}$, in Group B was $107.42 \pm 8.95 \mathrm{mmHg}$ and in Group $\mathrm{C}$ was $102.70 \pm 8.11 \mathrm{mmHg}$. During procedure heart rate and blood pressure were more stable in Group A as compared to Group B and Group C (Difference of mean $>\mathrm{CD}$ ).

Intubation was successful in all patients. The mean intubation time for Group A $(70.72 \pm 14.32 \mathrm{~s})$ was shorter than that for Group B $(127.83 \pm 33.30$ s) \& Group C (89.83 $\pm 25.34 \mathrm{~s})(\mathrm{P}=0.029)$.

Ease of intubation was significantly better in Group A as compared to Group B and Group C. Grade 0 is showed by $18,4,6$ patients in Group $\mathrm{A}, \mathrm{B}, \mathrm{C}$ respectively $(\mathrm{p}<0.01)$ showed by intubation grading scale. According to severity scale patients were more comfortable during procedure in Group A than Group C \& Group B. Grade 1 is showed by 20,6,6 in Group A,B,C respectively(p < 0.01).

Mean cough count were significantly lower in Group A(11) than Group B(26) \& Group C(23). Stridor was seen more in Group B(8) than Group $\mathrm{C}(2)$ \& Group $\mathrm{A}(0) .1$ patient in Group B and 1 patient in Group $\mathrm{C}$ required additional lignocaine during procedure.

Table 1 Demographic data

\begin{tabular}{|l|c|c|c|}
\hline Parameter & Group A & Group B & Group C \\
\hline $\begin{array}{l}\text { Age } \\
\text { (Years) }\end{array}$ & $36.13 \pm 11.23$ & $36.20 \pm 9.20$ & $33.20 \pm 9.23$ \\
\hline $\begin{array}{l}\text { Weight } \\
(\mathrm{Kg})\end{array}$ & $68.10 \pm 7.02$ & $69.93 \pm 7.22$ & $69.10 \pm 5.79$ \\
\hline
\end{tabular}

Fig 1 hemodynamic variables

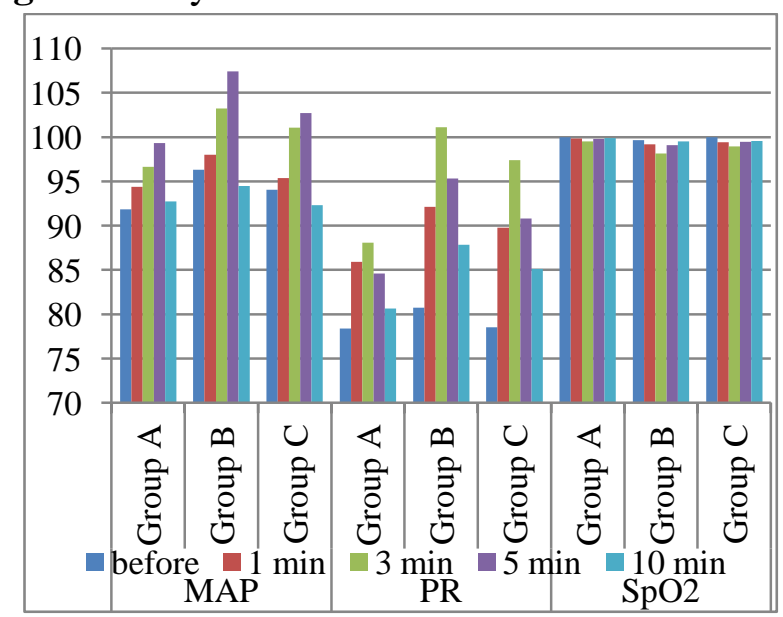




\section{JMSCR Vol||06||Issue||03||Page 1280-1285||March}

Table 2 Intubation time

\begin{tabular}{|l|c|c|c|}
\hline & Group A & Group B & Group C \\
\hline $\begin{array}{l}\text { Intubation } \\
\text { Time } \\
\text { (Seconds) }\end{array}$ & $70.72 \pm 14.32$ & $\begin{array}{c}127.83 \pm 33.3 \\
0\end{array}$ & $89.83 \pm 25.34$ \\
\hline
\end{tabular}

Table 3 Intubation grading scale

\begin{tabular}{|l|c|c|c|}
\hline $\begin{array}{l}\text { Intubation } \\
\text { grading } \\
\text { scale }\end{array}$ & $\begin{array}{c}\text { Group A } \\
\text { (number of } \\
\text { patients) }\end{array}$ & $\begin{array}{c}\text { Group B } \\
\text { (number of } \\
\text { patients) }\end{array}$ & $\begin{array}{c}\text { Group C } \\
\text { (number of } \\
\text { patients) }\end{array}$ \\
\hline 0 & 18 & 4 & 6 \\
\hline 1 & 8 & 9 & 11 \\
\hline 2 & 2 & 10 & 9 \\
\hline 3 & 1 & 4 & 2 \\
\hline 4 & 1 & 3 & 2 \\
\hline
\end{tabular}

Fig 2 Intubation grading scale

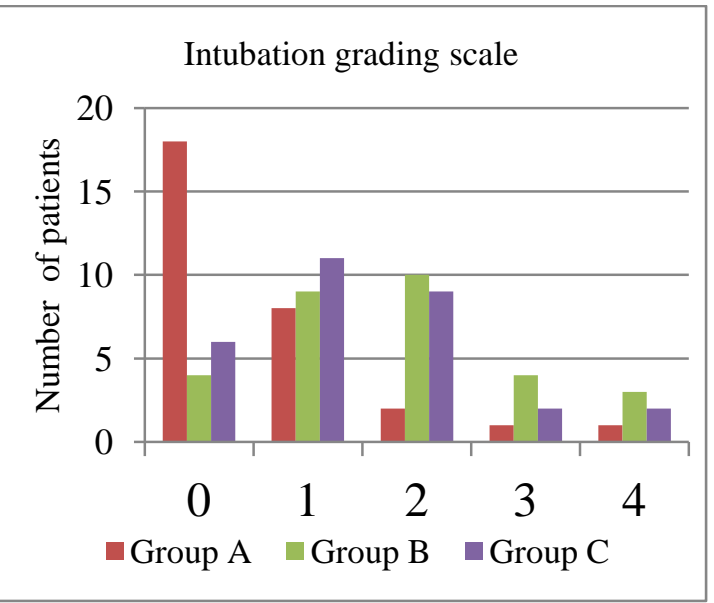

Table 4 Severity scale

\begin{tabular}{|l|c|c|c|}
\hline Severity Scale & $\begin{array}{c}\text { Group A } \\
\text { (number of } \\
\text { patients) }\end{array}$ & $\begin{array}{c}\text { Group B } \\
\text { (number of } \\
\text { patients) }\end{array}$ & $\begin{array}{c}\text { Group C } \\
\text { (number } \\
\text { of } \\
\text { patients) }\end{array}$ \\
\hline 1 & 20 & 6 & 6 \\
\hline 2 & 6 & 9 & 12 \\
\hline 3 & 2 & 11 & 10 \\
\hline 4 & 1 & 3 & 1 \\
\hline 5 & 1 & 1 & 1 \\
\hline
\end{tabular}

Fig 3 Severity scale

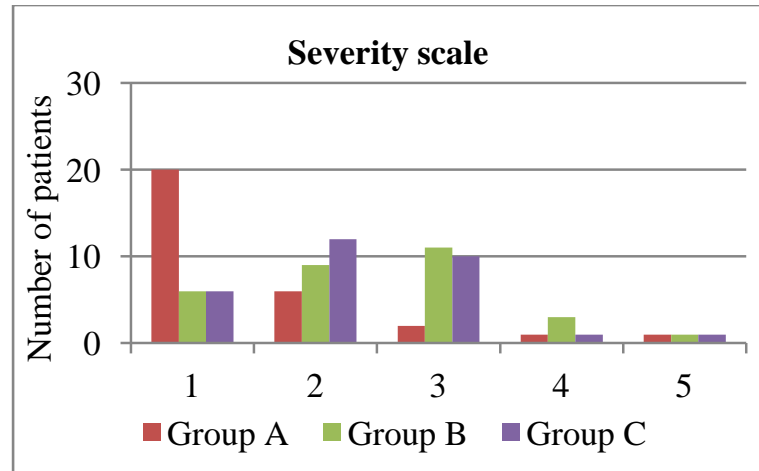

Table 5 Complications

\begin{tabular}{|l|c|c|c|}
\hline & $\begin{array}{c}\text { Group A } \\
\text { (number of } \\
\text { patients) }\end{array}$ & $\begin{array}{c}\text { Group B } \\
\text { (number of } \\
\text { patients) }\end{array}$ & $\begin{array}{c}\text { Group C } \\
\text { (number of } \\
\text { patients) }\end{array}$ \\
\hline Cough count & 11 & 26 & 23 \\
\hline stridor & 0 & 8 & 2 \\
\hline $\begin{array}{l}\text { extra } \\
\text { lignocaine }\end{array}$ & 0 & 1 & 1 \\
\hline
\end{tabular}

\section{Discussion}

Fiberoptic bronchoscope was designed and developed in 1966. The first fiberoptic nasotracheal intubation was performed with a fiberoptic choledoscope in a patient with still's disease $^{11}$. The use of fiberoscope was expanded to various aspects of airway management such as confirmation of proper placement of single and double lumen tubes, evaluation of airway pathology preoperatively and in intensive care unit, difficult airway management in both adults and children. Lignocaine is most commonly used local anaesthetic agent for fiberoptic intubation and has a wide margin of safety and absorption from respiratory mucosa is known to be rapid ${ }^{12}$.

The present work was carried out as a comparative, randomized, prospective study to evaluate and compare the three different methods used to achieve local anaesthesia for fiberoptic intubation under sedation in terms of subjective assessment by patients and endoscopist using intubation grading scale, severity scale, grading of overall intubating condition and objective measurement of cough, stridor, intubation time, any other complications and extra lignocaine required during procedure.

In our study hemodynamic variables were comparable before the procedure. During procedure heart rate and blood pressure were more stable in Group A as compared to Group B and Group C (Difference of mean $>C D$ ). Difference between Group B and Group C was insignificant during entire procedure (Difference of mean $<C D$ ). $\mathrm{SpO}_{2}$ was comparable between the groups. Kundra et $\mathrm{al}^{[13]}$ reported the increase in heart rate and mean arterial pressure was significantly greater in the nebulization group than in the combined regional block group. 
In our study, all patients were intubated successfully. The mean intubation time was significantly shorter in the transcricoid group; similar to the findings of Gupta et $\mathrm{al}^{[5]}$, who reported a mean intubation time of $123 \pm 46.7 \mathrm{~s}$ in a nerve block group and 200.4 $\pm 72.4 \mathrm{~s}$ in a nebulization group $(\mathrm{P}=0.047)$. Alka Chandra ${ }^{[14]}$ et al in 2011 found that mean time to reach carina was significantly lesser in transcricoid group $(57.33 \pm 12.98 \mathrm{~s})$ as compared to spray as you go group $(79.33 \pm 22.35 \mathrm{~s}) \quad$ during fiberoptic bronchoscopy $(p<0.02)$. However, Reasoner et $\mathrm{al}^{[15]}$ found no significant difference in intubation time between nerve block and topical anesthesia groups.

In our study, ease of intubation was better in transcricoid group compared with other groups, similar to the studies of Webb et al. ${ }^{[4]}$, Sethi et al. ${ }^{[16]}$. However, Reasoner et al. ${ }^{[15]}$ and Gupta et al. ${ }^{[5]}$ found no significant difference in intubating conditions between groups. It should be noted that scale for evaluating intubating conditions was different in previous studies, so we could not directly compare their intubating conditions with those of our study.

Quality of anaesthesia was significantly better in Group A as evidenced by significantly higher patients $(76.6 \%)$ showed procedure was not unpleasant (Grade 1). Similar to our study Graham et $\mathrm{al}^{[2]}$ reported that the transtracheal injection of cocaine provided significantly superior patient comfort and less coughing episodes as compared with rest of the techniques.

Mathur $\mathrm{P}$ et $\mathrm{al}^{[17]}$ found that intubating conditions for nerve block group were better than nebulization group $(p=0.001)$. Patient comfort assessed by cough severity $(\mathrm{p}=0.001)$ and intubation comfort scores $(\mathrm{p}=0.012)$, was higher in nerve block group than in nebulization group. However Lt Col Sethi et al ${ }^{[16]}$ found that quality of laryngeal anaesthesia was significantly better in spray as you go method as evidenced by lower severity scale $(\mathrm{p}<0.05)$. Grading of overall intubating condition was better for spray as you go group $(\mathrm{p}<0.01)$.
The control of coughing is of paramount importance for the quality of fiberoptic intubation. We recorded cough counts during the procedure as the mean count per procedure. The total number of coughs was significantly less in transcricoid group $\left.{ }^{(11}\right)$. Stridor was uncommon during nasal passage of fiberoscope in all groups. However after intubation 8 patients in Group B and 2 patients in Group $\mathrm{C}$ developed stridor, which is a reflection of inadequate laryngotracheal anaesthesia with "spray as you go" technique. Extra lignocaine was required in one patient in Group B and one patient in Group C. Other complications like local swelling, hematoma, subcutaneous emphysema were not seen in any of three groups similar to studies of Webb et $\mathrm{al}^{[4]}$.

Similar to our study Alka Chandra et al ${ }^{[14]}$ in 2011 found that the number of coughs in transtracheal group $(4 \pm 0.98)$ was significantly lesser than spray as you group $(4.9 \pm 1.24)$ during fiberoptic bronchoscopy $(\mathrm{p}<0.05)$. Graham et $\mathrm{al}^{[2]}$ found that transcricoid group produced less cough count $(\mathrm{p}<0.01)$ and easier tracheal intubation.

However Lt Col Sethi et $\mathrm{al}^{[16]}$ found that total number of coughs were significantly less in spray as you go group (12 patients) compared with transcricoid (18 patients) and nebulization group (all patients) $(\mathrm{p}<0.05)$.

\section{Conclusion}

Fiberoptic guided intubation under sedation with transcricoid injection of lignoacine can be recommended as a safe method of anaesthetizing the respiratory mucosa, which is well tolerated by patients and provides acceptable conditions for the endoscopist with negligible side effects as compared to nebulization of lignocaine or spray as you go method.

\section{References}

1. Benumof J. Management of the difficult adult airway with special emphasis on awake tracheal intubation. Anaesthesiology 1991;75:1087-110. 
2. Graham DR, Hay JG, Clague J, et al. Comparison of three different methods used to achieve local anaesthesia for fiberoptic bronchoscopy. Chest 1992;102:704-7.

3. Malcharek MJ, Bartz M, Rogos B, Günther L, Sablotzki A, Gille J, Schneider G. Comparison of Enk Fibreoptic Atomizer with translaryngeal injection for topical anaesthesia for awake fibreoptic intubation in patients at risk of secondary cervical injury: A randomised controlled trial. Eur J Anaesthesiol. 2015 Sep;32(9):615-23.

4. Webb AR, Fernando SSD, Dalton HR. Arrowsmith JE, Wood head MA, Cumrnin ARC. Local anaesthesia for fibreoptic bronchoscopy: transcricoid injection or spray as you go' technique? Thorax 1990;45:474-77.

5. Gupta B, Kohli S, Farooque K, et al. Topical airway anesthesia for awake fiberoptic intubation: Comparison between airway nerve blocks and nebulized lignocaine by ultrasonic nebulizer. Saudi Journal of Anaesthesia. 2014;8(Suppl 1):S15-S19.

6. Issac P A, Barry JE, Vaughan RS, Rosen M, Newcombe RG. A jet nebuliser for delivery of topical anaesthesia to the respiratory tract A comparison with cricothyroid puncture and direct spraying for fibreoptic bronchoscopy. Anaesthesia, 1990 Jan;45(1):46-8.

7. Putinati S, Ballerin L. Patient satisfaction with conscious sedation for bronchoscopy. Chest. 1999;115(5):1437-40.

8. Matot I, Kramer MR. sedation in outpatient bronchoscopy. Respir Med, 2000;94(12):1145-53.

9. Grendelmeier P, Kurer G, Pflimlin E, Tamm M, Stolz D. Feasibility and safety of propofol sedation in flexible bronchoscopy. Swiss Med Wkly. 2011 Aug 26;141:w13248.
10. Stolz D, Kurer G, Meyer A. Propofol versus combined sedation in flexible bronchoscopy, a randomized non inferiority trial. Eur Respir J. 2009;34(5):1024-30.

11. Murphy P. A fiberoptic endoscope used for nasal intubation. Anaesthesia. 1967;22:489-91.

12. Chaudhari L S, Manjrekar R P, Kamat S $\mathrm{K}$, Dasgupta D D. use of lignocaine in bronchoscopy. J Postgrad Med 1982;28:64.

13. Kundra P, Kutralam S, Ravishankar M. local anaesthesia for awake fiberoptic nasotracheal intubation. Acta anaesthesiol Scand 2000 May;44(5):511-6.

14. Chandra A, Banavaliker JN, Agarwal MK. Fibreoptic bronchoscopy without sedation: Is transcricoid injection better than the "spray as you go" technique?. Indian J Anaesth 2011;55:483-7.

15. K. Reasoner, Daniel \& Warner, David \& M. Todd, Michael \& W. Hunt, Scott \& Kirchner, Jerry. (1995). A Comparison of Anesthetic Techniques for Awake Intubation in Neurosurgical Patients. Journal of neurosurgical anesthesiology 1995;7(2):94-9.

16. Sethi N, Tarneja VK, Madhusudanan TP, Shouche S. Local anaesthesia for fiberoptic intubation : A comparision of three techniques. Med J Armed Forces India. 2005 Jan;61(1):22-5.

17. Mathur PR, Jain N, Kumar A, Thada B, Mathur V, Garg D. Comparison between lignocaine nebulization and airway nerve block for awake fiberoptic bronchoscopyguided nasotracheal intubation: a singleblind randomized prospective study. Korean J Anesthesiol. 2017 Jan;70:e54. 